\title{
Equilibrium mergers in a composite good industry with efficiencies
}

\author{
Cristina Pardo-Garcia • Jose J. Sempere-Monerris
}

Received: 7 April 2014 / Accepted: 8 December 2014 / Published online: 20 December 2014 (C) The Author(s) 2014. This article is published with open access at SpringerLink.com

\begin{abstract}
This paper studies equilibrium merging behavior in composite good industries. Component producers face the option to either merge with a similar component producer (horizontal merger) or a complementary one (vertical merger) of a composite good. Focusing only on strategic reasons, vertical mergers arise at equilibrium only when composite goods are very differentiated or when the number of producers is large while horizontal mergers arise otherwise. When efficiencies are considered, higher marginal cost savings are required for a horizontal merger in a composite industry not to result in a price increase as compared with those required for a regular industry. This finding can be used by antitrust authorities to be more demanding when dealing with horizontal mergers in composite goods industries.
\end{abstract}

Keywords Composite goods - Substitutes - Complements · Horizontal merger · Vertical merger $\cdot$ Efficiency effects $\cdot$ Diversion ratio

JEL Classification $\quad$ L13 $\cdot$ L41

\footnotetext{
C. Pardo-Garcia

Department of Applied Economics, University of Valencia, Campus dels Tarongers,

46022 Valencia, Spain

e-mail: Cristina.Pardo-Garcia@uv.es

J. J. Sempere-Monerris ( $\square)$

Department of Economic Analysis and ERI-CES, University of Valencia,

Campus dels Tarongers, 46022 Valencia, Spain

e-mail: Jose.J.Sempere@uv.es

J. J. Sempere-Monerris

CORE-UCL, Voie du Roman Pays, 34, 1348 Louvain-la-Neuve, Belgium
} 


\section{Introduction}

Consumers derive utility from consumption of different sort of goods, some of them are consumed separately and others used in combinations instead. There are combinations in which individual components provide utility as well, such as a flight and a hotel booking; while in others utility is only derived when both components are used simultaneously, such as mobile phones and mobile phone services, ${ }^{1}$ hardware and software, printers and ink cartridges or an e-book file and a device to read it. Industries involved in those products are significant for developed economies. For example the mobile phones market valued at Retail Selling Price is worth 16,702 millions of dollars in North America and 37,765 millions of dollars in Western Europe in 2011. Consumer expenditure on telecommunications services is about 247,855 millions of dollars in North America and 242,323 millions of dollars in Western Europe in 2012. ${ }^{2}$ Industries developing those products are typically concentrated and firms are in constant search for increased profitability. Then, several interesting questions raise: Is it more profitable for a component producer to merge with a substitute or with a complement component producer? What will authorities do? What's the role of efficiencies in these scenarios?

Note that the first question above is interesting and also pertinent. The second merger in deal value importance in 2012 was between Starburst II Inc (dependent from the Japanese firm Softbank Corp, the acquirer) and Sprint Nextel Corporation (the target) and amounted to 36,956 millions of dollars. ${ }^{3}$ Both firms offer wireless networks and mobile communication services. The proposed merger is therefore between substitute component producers, while Starburst II Inc had potentially the option to merge with a mobile phone producer such as the Japanese firm Kyocera, that is, with a complement component producer. Thus, it is relevant to understand which are the reasons behind the Starburst decision.

The main purpose of the paper is to analyze the equilibrium merging behavior in composite good industries, that is when firms face the option to either merge with a competitor that is producing a similar component (same type) or a complementary component (different type) of a composite good. The first type of merger will be denoted horizontal merger, while the second one vertical merger. ${ }^{4}$ Mergers are useful devices to restructure industries ${ }^{5}$ and one of the most scrutinized firms' decisions by competition authorities. During 2012 the Federal Trade Commission (FTC) has

\footnotetext{
1 In Spain it is common to choose a mobile phone and a network according to an offer, this combination of device and network is unique, but there are other offers with different devices, or different networks.

2 Data from Passport GMID by Euromonitor.

3 Data from Zephyr Annual M\&A Report 2012, published by BvD.

4 Vertical mergers entail expanding forward or backward in the chain of distribution, toward the source of raw materials or toward the ultimate consumer. In our case such a vertical relation does not exist, however we will keep the label "vertical" for the sake of exposition.

5 The number of mergers and acquisitions in 2012 reached 19,600 in Western Europe and 14,800 in the US and Canada. While these figures corresponding to 2013 are 21,700 and 14,500 respectively. Despite the worldwide economic crisis, the number of deals is still relevant (Zephyr Annual M\&A Reports 2012 and 2013, published by BvD).
} 
actively used litigation to block proposed mergers and unwind allegedly anticompetitive consummated mergers, for instance in December 2012 the FTC filed a complaint seeking to deter Integrated Device Technology's acquisition of PLX Technology in the hardware industry. Similarly, the recent Department Of Justice (DOJ)'s challenge to the Anheuser-Busch InBev/Grupo Modelo transaction in the beer industry. Regarding the European Commission (EC), over the past three years, the rate at which notified mergers initiate a Phase II investigation has almost tripled, from $1.19 \%$ in 2010 to $3.53 \%$ in 2012. Finally, 2012 witnessed the third (UPS's acquisition of TNT Express) fourth (the proposed takeover of Aer Lingus by Ryanair) and fifth (the merger between Deutsche Börse and NYSE) merger prohibition since 2007.

However, while vertical mergers are pleasantly received, horizontal ones are usually considered harmful for consumers and society. ${ }^{6}$ Thus our second purpose in the paper is to provide some analysis that might be useful for competition authorities to better understand the effects of horizontal mergers in composite good industries. In doing so, we will draw comparisons on the variation between post and pre merger prices in relative terms resulting from a horizontal merger in a composite industry and the one in a regular industry. Also on how synergies resulting from horizontal mergers affect that index depending on the good considered. ${ }^{7}$

To answer the above questions, we will present a model that allows firms to choose the type of merger. Then, consider an industry of composite goods formed by two components, $A$ and $B$. There are $n$ independent firms producing varieties of component $A$ and $\mathrm{n}$ firms producing varieties of its complementary component $B$. Components' compatibility results in $n \times n$ composite goods in the market. We assume consumers choose components to create their own composite goods and get utility, since consuming separate components is useless. Therefore, composite goods compete as imperfect substitutes, but at the same time different type components are complements while same type components are also substitutes. The proponent firm chooses between merging with a substitute component producer, with a complementary component producer or remaining alone. Focusing on strategic effects, we find that a vertical merger is privately preferred only when composite goods are very differentiated or when the number of firms is greater than 11, the horizontal merger is chosen otherwise. ${ }^{8}$ Therefore horizontal mergers are more suitable tools rather than vertical ones to increase business profits when products are less differentiated and the

\footnotetext{
6 Nevertheless, horizontal mergers are frequently proposed and accepted by antitrust authorities. For example, a merger between two of the six major publishing companies, Random House and Penguin Group (Pearson) has been recently announced. It will reach a turnover of $€ 3,000$ million. The new firm, Penguin Random House, has been approved by antitrust authorities from US, New Zealand, Australia, EU, Canada, South Africa and China, all of them without conditions.

7 The index used is related to the Compensating Marginal Cost Reductions (CMCR) concept that was initially proposed by Werden (1996) and by Froeb and Werden (1998). It is also related to the Upward Pricing Pressure Index (UPPI) in its more accurate version. The UPPI have been recently incorporated by Farrell and Shapiro (2010) to evaluate potential unilateral effects in mergers and included in the US Horizontal Merger Guidelines issued in 2010 by the USDOJ and FTC (U.S. Department of Justice and the Federal Trade Commission 2010).

8 Both mergers are qualitatively different, not only by the component combinations, but also because the vertical merger allows more pricing strategies (pure bundling and mixed bundling).
} 
number of composite goods available in the market is not very large, i.e. greater than 121. The Cournot effect derived from a vertical merger, that is the price reduction for two complements when they are sold by the same firm rather than by separate monopolists, is dominated by the competition effect resulting from a horizontal merger, that is the acquisition of greater market power derived from the internalization of competition within substitutes through the partial monopolization of one component. Two interesting policy implications are reached: (i) when only strategic effects are reckoned, proposed vertical mergers have to be always cleared while proposed horizontal mergers must be always blocked by antitrust authorities. And (ii) merger proposals different from the equilibrium ones are sufficient conditions for antitrust agencies to infer substantial efficiencies not considered that justify those proposals. Focusing on the case of $n=2$, the above results and policy implications are most of the times qualitatively robust to the consideration of alternative assumptions such as different number of producers for each component, three components instead of two, not compatible components and differences in quality among firms producing the same component. Several asymmetries arise between firms in industries with such alternative assumptions, what makes the equilibrium merger be sensitive to the identity of the proposer. However, the socially optimal merger maintains basically the same pattern with some variations in the ranges for the differentiation ratio required to clear vertical mergers.

If firms do the same activity, it seems natural to consider costs savings after a merger due to the similarity in production of both components. ${ }^{9}$ Efficiencies are obtained from the rationalization of production, economies of scale, technological progress (knowhow, R\&D), purchasing economies or savings in factor prices. ${ }^{10}$ If efficiency gains are sufficiently large to extend the benefits to consumers, then antitrust authorities have reasons to clear proposed horizontal mergers. Then a direct question raises, which is this minimum required efficiency to clear a horizontal merger in a composite good industry? In order to answer this question the level of marginal cost saving that results in a non-increase in the price index used is computed. We find that a greater marginal cost saving is required for a horizontal merger in a composite good industry not to increase prices as compared with a horizontal merger in a regular good industry. The above result is interesting for antitrust authorities since it advises them to be more demanding when dealing with horizontal mergers in composite goods industries. We would like to note that this difference is rooted to the higher diversion ratio and margin that arise in composite good industries.

\section{The received literature}

Salant et al. (1983) initiates the analysis of the strategic motives for exogenous mergers. The main finding being that mergers of Cournot oligopolists producing substitute goods are unprofitable unless they include enough participants, while outsiders are

\footnotetext{
9 In the empirical paper by Gayle and Le (2013) two real mergers between airline companies are studied. They found evidence of fixed and marginal cost savings in both cases. In another industry, Harrison (2011) found that hospital mergers involved cost savings, which are greater the first post-merger year than the following ones.

10 For an exhaustive analysis about efficiency gains from mergers see Röller et al. (2001).
} 
always better off. ${ }^{11}$ Gaudet and Salant (1992) extend SSR's analysis to complementary goods and price competition, getting the same conclusions about merger profitability but opposite welfare outcome. Beggs (1994) studies merging decisions in a setting of two groups with two firms each, where products are complements within the group but substitutes across groups and no compatibility is assumed. Firms producing complements usually prefer acting independently instead of merging. Economides and Salop (1992) analyze the price effects derived from different exogenous market structures in an industry with two brands for each compatible component and no bundling strategies. Choi (2008) takes Economides and Salop's framework to study strategic motives to engage only in complementary mergers allowing for mixed bundling. ${ }^{12}$ Our contribution to the merger literature hinges on the case in which consumers assemble the components of composite goods and only joint consumption yields utility. We wish to move a step forward by addressing the incentives to merge when two types of merger are possible in the same industry: among same type component producers or among different type ones.

The binomial mergers-efficiency effects is considered since Perry and Porter (1985) who state that incentives to merge depend on two effects: price increases and output decreases. Allowing for a larger merged firm (with lower marginal cost) than previous independent firms, the output reduction is softer than in SSR. Farrell and Shapiro (1990) present internal efficiencies where firms have different costs, showing that economies of scale or learning effects needed for a merger to decrease prices are greater the larger are the market shares of the merging firms and the less elastic is industry demand. ${ }^{13}$ More recent papers focus on dynamic models of endogenous mergers, as Motta and Vasconcelos (2005) and Vasconcelos (2010), where a comparison is established between myopic and forward looking antitrust authorities. The former paper shows that if efficiencies are strong, prices might be lower after the merger, even if some firms exit. The efficiency offense argument cannot be sustained with forward looking antitrust authorities, since rival firms will engage in a merger as well. The latter paper focuses on structural remedies in merger control, which are not needed to implement the preferred market structure with forward looking authorities but they are necessary for optimal decisions with myopic ones. Banal Estañol et al. (2008) focus on questioning the realization of efficiencies. If antitrust authorities take them for granted, mistakes are found in both sides: approving welfare-reducing mergers and blocking welfare-enhancing ones. Closer to our model is Motta (2004), who finds a sufficient level of efficiency gains for a horizontal merger to be beneficial for consumers

\footnotetext{
${ }^{11}$ In Deneckere and Davidson (1985) every merger is profitable, due to upward-sloping reaction functions. Kamien and Zang (1990) develop a two-stage game of endogenous mergers in a market with homogenous products, finding that full monopolization of an industry is not the usual result.

12 In the case consumers also obtain utility by consuming the components separately, Flores Fillol and Moner Colonques (2011) find that merging is a dominant strategy with soft competition and incentives to merge are higher if component demands are not too important.

13 An extension to this model and Werden and Froeb (1998) but allowing for entry is Spector (2003) who finds that profitable mergers with no technological synergies are harmful for consumers regardless of fixed costs or entry conditions. Efficiencies and free-entry are also studied in Cabral (2003), who states that a merger defense based on cost efficiencies changes if post-merger entry is allowed, because there is a more efficient firm. However, entry will be less likely since new rivals will face tougher price competition.
} 
when firms choose prices in a static framework. We extend it by analyzing a composite good industry with differentiated goods finding the required synergy which implies a non-increase in prices and how it compares with a regular good industry.

Next section describes the model and presents the type of merger which is preferable from a private and a social point of view. It also include a subsection with the rivals reaction to a former merger and a robustness subsection. In Sect. 3 the model is extended to include efficiencies in marginal cost, a price variation index corresponding to the Horizontal merger in a composite good industry is provided and compared with the one that would arise if the industry would not be a composite good one. Section 4 concludes.

\section{The model}

Consider a situation where consumers need to combine two complementary components, $A$ and $B$, in fixed proportions on a one-to-one basis, to form a composite good because they only get utility by consuming composite goods. The industry consists of $n \times n$ initially independent firms, $n$ of them producing type $A$ components, denoted by $i$ with $i=1,2, \ldots, n$ and the other $n$ producing type $B$ components, denoted by $j$ with $j=1,2, \ldots, n$. Full compatibility is assumed, that is any component of one type is fully compatible with any other component of the different type, therefore up to $n \times n$ different composite goods can be consumed, i.e. $A_{1} B_{1}, A_{1} B_{2}, \ldots A_{1} B_{n-1}$, $A_{1} B_{n}, \ldots A_{n} B_{1}, A_{n} B_{2}, \ldots A_{n} B_{n}$.

Note that the underlying market is one where both substitute and complement components are strategically linked, but consumers only choose among substitute composite goods. The quantity consumed of composite good $A_{i} B_{j}$ is denoted by $X_{i j}$ where subscript $i j=11,12, \ldots, 1 n, \ldots, n 1, \ldots n n$ refers to all composite goods mentioned above. The price of component $A_{i}$ is denoted by $p_{i}$ while the price of component $B_{j}$ is denoted by $q_{j}$. Therefore, composite good or system $i j$ is available at price $s_{i j}=p_{i}+q_{j}$. The system of demand functions is obtained considering a representative consumer product differentiation model, with the following utility function: ${ }^{14}$

$$
U=y+\alpha\left(\sum_{\forall i}\left(\sum_{\forall j} X_{i j}\right)\right)-\frac{\beta-\gamma}{2}\left(\sum_{\forall i}\left(\sum_{\forall j} X_{i j}^{2}\right)\right)-\frac{\gamma}{2}\left(\sum_{\forall i}\left(\sum_{\forall j} X_{i j}\right)\right)^{2}
$$

where $\alpha, \beta, \gamma>0$ are the demand parameters in the model and $y$ is the quantity of numeraire good consumed. Utility maximization under the following budget constraint, $I=y+\sum_{\forall i j} s_{i j} X_{i j}$ leads to the next system of inverse demand functions, $s_{i j}=\alpha-(\beta-\gamma) X_{i j}-\gamma \sum_{\forall k l} X_{k l}, \forall i j$ where $i, j, k, l \in\{1,2, \ldots, n\}$. Finally, by inverting the above system, the next system of demand functions is reached,

\footnotetext{
14 In fact, this is reformulation of the commonly used utility function that is easier to manipulate for an arbitrary number of products.
} 


$$
X_{i j}=\frac{\alpha(\beta-\gamma)-\left(\beta+\left(n^{2}-1\right) \gamma\right) s_{i j}+\gamma \sum_{\forall k l} s_{k l}}{(\beta-\gamma)\left(\beta+\left(n^{2}-1\right) \gamma\right)} \forall i j
$$

As indicated above composite goods are imperfect substitutes, own effects in demand are negative and greater, in absolute value, than cross effects if condition $\beta>\gamma$ holds. This condition is standard and simply says that an increase of the same amount in all prices will imply a decrease in demand. Finally, as parameter $\gamma$ approaches $\beta$, composite goods become more similar (less differentiated) to consumers and in the extreme case where $\gamma$ equals zero all goods become independent. ${ }^{15}$ Regarding component production costs, and to simplify the model as much as possible, it is assumed that marginal costs are constant, common and equal to $c$. Firms profits are $\pi_{A_{i}}=\left(p_{i}-c\right) \sum_{\forall j} X_{i j}$ and $\pi_{B_{j}}=\left(q_{j}-c\right) \sum_{\forall i} X_{i j}$ for component type $A$ and $B$ producers, respectively.

In this initial situation, each firm in the industry is identified with a single component which is used by consumers to assemble the $n$ different composite goods containing such a component. We are interested in finding the initial Nash equilibrium in prices. Each firm chooses the component price to maximize profits. Equilibrium prices of every component, the total amount of output sold by a given producer and producer's profits read as follows, where superscript $I$ is denoting the initial situation and emphasize that variables are function of $n:{ }^{16}$

$$
\begin{gathered}
p_{i}^{I}=q_{j}^{I}=p^{I}(n)=\frac{(\beta-\gamma)(\alpha-2 c)}{3 \beta+\left(n^{2}-n-3\right) \gamma}+c \\
\sum_{\forall j} X_{i j}^{I}(n)=\sum_{\forall i} X_{i j}^{I}(n)=\frac{n\left(\beta+\left(n^{2}-n-1\right) \gamma\right)(\alpha-2 c)}{\left(\beta+\left(n^{2}-1\right) \gamma\right)\left(3 \beta+\left(n^{2}-n-3\right) \gamma\right)} \\
\pi_{A_{i}}^{I}=\pi_{B_{j}}^{I}=\pi^{I}(n)=\frac{n(\beta-\gamma)\left(\beta+\left(n^{2}-n-1\right) \gamma\right)(\alpha-2 c)^{2}}{\left(\beta+\left(n^{2}-1\right) \gamma\right)\left(3 \beta+\left(n^{2}-n-3\right) \gamma\right)^{2}}
\end{gathered}
$$

Consider now that one firm decides to merge with another. Without loss of generality, along the merger proposal $A_{1}$ is arbitrarily chosen to be the proposer, that is, the firm deciding whom to merge with. The other part, the respondent, can either accept or reject it. If a proposed merger is profitable as a whole, any respondent will undoubtedly accept it, since the proposer will offer the same profits earned the previous period plus an epsilon to the respondent. Only mergers that will be accepted at equilibrium will be proposed. Two different kinds of merger can be proposed depending on the

\footnotetext{
15 Notice that it is assumed that all rival composite goods are symmetric imperfect substitutes, although it would be more natural to assume composite goods sharing one component to be closer substitutes than the composite good with no shared component. However, this complication in the analysis is not fully justified since no important differences in results are obtained.

16 Each firm is setting one part of the composite good price for $n$ different composite goods. Then, by reducing its price, it is getting a positive effect equal to the sum of the production sold in every of its composite goods and a negative effect with is proportional to the margin and also to a term which increases with $\gamma$ and $n$. As a consequence larger $\gamma$ or $n$ induce both lower equilibrium prices and quantities, with margins decreasing at a larger rate.
} 
identity of the respondent, either a horizontal merger, denoted by $H$, if another firm of the same type to the proposers is chosen or, a vertical merger, denoted by $V$ if the respondent is a type- $B$ producer.

\section{The horizontal merger analysis}

Consider a merger between the two producers of the same type of components, e.g. the $A_{1} A_{2}$ merger. Firms not participating in the merger are named as the outsiders. There are outsiders of each type when $n>2$. The new firm partially internalizes competition among composite goods by partially monopolizing one component in the market. Equilibrium prices and profits can be found in the Appendix. Superscript $H$ identifies the horizontal merger case and subscripts $M$ and $O$ refer to the prices set by the merger and by the outsiders, respectively. The following ranking identifies the effect of a $H$ merger in the market: $p_{M}^{H}(n)>p_{O}^{H}(n)>p^{I}(n)>q_{O}^{H}(n)$.

Partial monopolization by a $H$ merger will lead to increases in the prices of the components that are directly affected by the merger, e.g. $p_{i}$, and reductions in the prices corresponding to the other type of component. The reason is that the marginal benefit is now larger at any price for the new entity, thus leading to a higher equilibrium price which results by strategic substitutability among $p$ 's and $q$ 's to lower q's and by strategic complementarity among $p$ 's to higher p's. Besides, the differences in component prices shown in the above ranking are decreasing in the number of firms in the market. However, consumers react to composite good prices. Notice that, if $n>2$, consumers can obtain composite goods either including one component of the merged firm or just using components produced by outsiders. The former are sold at a higher price as compared to the initial situation and also at a higher price than those formed with outsider's components. However, the latter can be sold at a lower price as compared to the initial situation, i.e. $p_{O}^{H}(n)+q_{O}^{H}(n)<2 p^{I}(n)$, this occurs if and only if $\frac{\gamma}{\beta}<\frac{1}{n^{2}+1}$. Meaning that when products are differentiated enough a $H$ merger may lead to reductions in composite good prices.

Several comments are in order. First, the merged firm is better off offering the full range of components rather than restricting them. The reason is that more composite goods in the market allow the merged entity to capture greater share of industry profits, at the expense of outsiders. Second, there is always an incentive to form a $H$ merger. Third, outsiders of the same type are better off after a $H$ merger, while outsiders of different type are worse off, as a consequence the $H$ merger implies a shift in profits from type B component producers to type A ones. Finally industry profits after the merger might decrease if composite goods are very differentiated since losses in different-type outsiders offset gains by the merged entity and same-type outsiders. As products become more homogeneous all profits decrease, but the merged entity is able to deal better with the increase in competition since it has more market power than firms only controlling one component.

\section{The vertical merger analysis}

Consider now a merger between two producers of different components: e.g. the $A_{1} B_{1}$ merger. The new entity is able to implement a mixed bundling pricing strategy, that is, it selects three prices $p_{1}, q_{1}$ and the bundle price $s_{b}$, where at equilibrium, $s_{b}<p_{1}+q_{1}=s_{11}$. The demand system must then be reformulated substituting $s_{11}$ for 
$s_{b}$, as now composite good $A_{1} B_{1}$ is only demanded as a bundle, since it offers a discount on price. ${ }^{17}$ This implies that the merger now gets revenues from directly selling one composite good (i.e. the bundle $X_{11}$ ) and from the selling of two components which are combined by consumers to form $2(n-1)$ mix-and-match composite goods (i.e. $X_{1 j}$ for $j \neq 1$ and $X_{i 1}$ for $\left.i \neq 1\right)$. The remaining $(n-1) \times(n-1)$ composite goods are totally controlled by outsiders. The new entity and outsiders maximize profits by choosing prices. The equilibrium prices are listed in the Appendix and can be ranked as follows: $p_{M}^{V}(n)>p^{I}(n)>p_{O}^{V}(n)$, for the component prices and $s_{M O}^{V}(n)>s^{I}(n)>s_{O}^{V}(n)>s_{b}^{V}(n)$, for the composite good prices. Superscript $V$ denotes Vertical, while subscripts $O, M O$ and $b$ are denoting outsiders, mixand-match composite goods and the bundle, respectively. Notice, that both types of outsiders price their components at the same level, $p_{O}^{V}(n)$, since they face identical strategic conditions. The effect of a vertical merger is then an increase in the component prices produced by the merger and a reduction in components produced by outsiders as compared to the initial situation. Focusing on composite good prices, mix-and-match composite goods are sold at a higher price than composite goods before the merger (i.e. $s_{M O}^{V}(n)>s^{I}(n)$ ), while composite goods assembled using outsider components are priced lower, $s^{I}(n)>s_{O}^{V}(n)$. Finally, the bundle reaches the lowest price. As it might occur in a $H$ merger, we find that some composite goods increase their price while others do not after a merger. Thus, the general presumption that mergers between complements lead to lower prices is not completely true. This happens because the merger increases its single component prices to benefit its bundle demand, in detriment of mix-and-match composite goods demands. The effects on prices of a merger are smoothed as the number of firms increase. Notice that,in contrast with the Horizontal merger case, the consideration of more than two firms per component is not implying a qualitative change.

However, it turns out that mixed bundling can be improved upon by the merged entity only focusing on the selling of the bundle and stop selling $A_{1}$ and $B_{1}$ components separately (i.e. pure bundling). The following result identifies under which conditions mixed bundling will be chosen:

Result 1 The merged entity is better off implementing mixed bundling either if $n \geq 4$, or for $2 \leq n<4$ when composite goods are rather differentiated, i.e. for $\frac{\gamma}{\beta}<0.665$ if $n=2$, and $\frac{\gamma}{\beta}<0.883$ if $n=3$. Pure bundling arises at equilibrium otherwise.

The reason is that close substitutability among composite goods imposes at equilibrium too high component prices in order to keep the bundle appealing, thus ending up in a situation where it is better not to serve the mix-and-match markets. Since more firms in the market smooths price differentials, this effect disappears for $n>3$.

In fact, when pure bundling is used at equilibrium, the strategic effect is completely twisted since $s_{p b}^{V}(n)>s_{p O}^{V}(n)>s^{I}(n)$, where the $p$ in the subscript is referring to the pure bundling case. The unilateral effect of a vertical merger is to increase prices upon the initial situation, which is followed by another increase in outsider prices ending up in a situation that harms consumers.

17 As noted by Tirole (2005): "buying the bundle is really the only feasible option if the prices of the individual products are high". 
Interestingly, the incentive to merge is always positive and increasing with $n$ only if products are very differentiated, otherwise this incentive is decreasing. The outsiders' reaction is larger when products are close substitutes reducing the potential gains for the new entity. So that the incentive to merge for a given $n$ is decreasing in the $\frac{\gamma}{\beta}$ ratio. The new entity's strategic superiority (three strategic variables) is used to drain profits from both the composite goods produced by outsiders and the mix-and-match ones to the bundle. In fact the new entity gets more profits with the selling of the bundle than the pre-merger profits corresponding to the same composite good. This profits increase suffices to cover the reduction in profits coming from the mix-and-match composite goods. The Vertical merger imposes a negative externality (when mixed bundling is in place) on outsiders profits since they are compelled to reduce margins without getting a higher market share. The combination of both effects leads to a decrease in industry profits after the merger for intermediate values of product differentiation, since in such a case the increase in profits realized by the new entity is more than compensated by the reduction of outsiders' profits when the merger undertakes mixed bundling. Finally, when the merger undertakes pure bundling and composite goods are sufficiently close all firms increase their profits after a merger leading to an increase in industry profits.

\section{The equilibrium merger}

After describing the effects of each type of merger, we are interested in finding which one yields higher profits, that is, the sign of $R\left(n, \frac{\gamma}{\beta}\right) \equiv \pi_{M}^{H}(n)-\pi_{M}^{V}(n)$, or more precisely in the $\frac{\gamma}{\beta}$ that solves $R\left(n, \frac{\gamma}{\beta}\right)=0$ for each $n$. Although there is not a closedform solution, it is found that the limit of $R$ is negative when $\gamma$ tends to zero, which implies that when composite goods are not very much related a $V$ merger is always implemented. Besides, when $\frac{\gamma}{\beta}$ tends to one, that is if composite goods are close to perfect substitutes, then a $H$ merger is implemented only when $n<11,{ }^{18}$ otherwise only $V$ mergers will be observed at equilibrium. We also know that when the number of firms in between 2 and 11 then, $V$ mergers will only arise at equilibrium for small enough values of the $\frac{\gamma}{\beta}$ ratio, noticing that the threshold in $\frac{\gamma}{\beta}$ changes in a nonmonotone way as $n$ increases. In Table 1 below we have included the precise thresholds in $\frac{\gamma}{\beta}$ for several $n$. In the next Proposition the conditions for each type of merger to endogenously arise are summarized. ${ }^{19}$

Proposition 1 The equilibrium merger that will arise in a composite goods market depends on both how differentiated the composite goods are and the number of firms producing each component as follows:

The $V$ merger will be the equilibrium one either when products are very differentiated and $n<11$ or always if $n \geq 11$; the $H$ merger is the equilibrium one otherwise.

In Choi (2008) only vertical mergers are considered, however, when firms also have the option to create a horizontal merger and the number of firms producing components

\footnotetext{
18 Notice that this restriction implies up to 20 firms in the market and no less than 100 composite goods competing, then it fits with a large number of oligopoly industries.

19 Proofs are available upon request from the authors. Note that differences in profits only depend on the number of firms and the differentiation ratio. Then, for a given $n$, it is easy to compute the required $\frac{\gamma}{\beta}$.
} 
Table 1 Equilibrium mergers

\begin{tabular}{lll}
\hline Number of firms & Differentiation ratio & Private decision \\
\hline$n=2$ & If $0<\frac{\gamma}{\beta} \leq 0.0958$ & V proposed \\
& If $0.0958<\frac{\gamma}{\beta}<1$ & $\mathrm{H}$ proposed \\
$n=3$ & If $0<\frac{\gamma}{\beta} \leq 0.0819$ & $\mathrm{~V}$ proposed \\
& If $0.0819<\frac{\gamma}{\beta}<1$ & $\mathrm{H}$ proposed \\
$n=5$ & If $0<\frac{\gamma}{\beta} \leq 0.0741$ & $\mathrm{~V}$ proposed \\
& If $0.0741<\frac{\gamma}{\beta}<1$ & $\mathrm{H}$ proposed \\
$n=7$ & If $0<\frac{\gamma}{\beta} \leq 0.0833$ & $\mathrm{~V}$ proposed \\
& If $0.0833<\frac{\gamma}{\beta}<1$ & $\mathrm{H}$ proposed \\
$n=9$ & If $0<\frac{\gamma}{\beta} \leq 0.1297$ & $\mathrm{~V}$ proposed \\
& If $0.1297<\frac{\gamma}{\beta}<1$ & $\mathrm{H}$ proposed \\
$n \geq 11$ & Always & $\mathrm{V}$ proposed \\
\hline
\end{tabular}

is not too large, vertical mergers only arise for low values of the $\frac{\gamma}{\beta}$ ratio, while a $H$ merger is privately preferred otherwise. If $\frac{\gamma}{\beta}$ is close to zero composite goods are very differentiated and competition is not intense, thus the merged firm prefers to fully control one composite good through a vertical merger. In this way the new entity benefits from the so-called Cournot effect, the price reduction for two complements when they are sold by the same firm rather than by separate monopolists. The merger leads to a reduction in both complement prices, since the new firm captures the demand increase in the composite good when it lowers the other component's price. As $\frac{\gamma}{\beta}$ increases, composite goods are less differentiated and competition is more intense. Prices are already rather low, so a merger between complements makes prices decrease even more, and this makes the vertical merger less profitable. Then, it is preferable to internalize the effects of competition within substitutes, the competition effect, by partially monopolizing one component type. In this way, the merger controls one component in $2 n$ composite goods, increasing its market power. The above argument works out even for the case where the $V$ merger implies pure bundling. Then, $H$ mergers are more suitable tools rather than $V$ ones to increase business profits when the number of firms is lower than 22. The Cournot effect is dominated by the competition effect. ${ }^{20}$ Considering composite goods changes the intuition we have about the effects in the market of increasing the number of competitors. One more component producer is not only increasing competition in the market but also allowing existing firms to sell more composite goods that were not previously available. As a consequence, if composite goods are very much differentiated, the increase in demand may offset the increase in competition so firms get more profits with more firms in the market. The Cournot effect is capitalizing this effect as it is larger than the competition effect when composite goods are very differentiated. When, given $n$, competition becomes tougher

\footnotetext{
${ }^{20}$ In case of considering both strategic effects and efficiencies, the aggregate effect of each type of merger will determine which merger arises at equilibrium. Then, if the efficiencies are larger after a vertical merger, such type of mergers will be proposed in a larger range of the differentiation ratio.
} 
because composite goods are more substitutable, the competition effect is less affected by the increase in competition. However, as the number of firms increase, the gain derived from a $H$ merger is decreasing more quickly than the gain derived from a $V$ one.

\section{The socially optimal merger}

Finally, to answer our initial research question, it is important to analyze whether the proposed mergers arising from the previous subsection would be cleared by antitrust authorities. Antitrust authorities make decisions based on how the proposed merger affects either Consumer Surplus (CS) or Social Welfare (SW) standards. To obtain the Social Welfare measure we take the utility function and subtract the costs paid by firms. Then, to obtain Consumer Surplus, we have to subtract the profits of all firms in the market to the Social Welfare. The precise expressions can be found in the Appendix. Which merger is socially preferred is in the next proposition.

Proposition 2 The highest level of Social Welfare, which is a function of the degree differentiation, is attained as follows: (i) through a $V$ merger if composite goods are enough differentiated; (ii) or not clearing any type of merger otherwise.

The highest level of Consumer Surplus is attained under qualitatively similar situations as for the Social Welfare case, with the difference that a V merger is cleared for a larger interval of the differentiation ratio.

Finally, the condition for a vertical merger to be cleared becomes more restrictive as the number of component producers increases, irrespective of the standard used.

Table 2 includes the precise conditions for a $V$ merger to be cleared under both standards and how they vary according to the number of component producers. As already established in the previous subsection, after an $H$ merger component prices react in a way that induce increases in the composite good prices with one of the components controlled by the new entity, and also reductions in those composite goods made up with outsider's components. However, the overall effect is that consumer

Table 2 Clearance conditions under the CS and SW standards

\begin{tabular}{lllll}
\hline Number of firms & CS Standard & & SW Standard & \\
\hline$n=2$ & If $0<\frac{\gamma}{\beta} \leq 0.6259$ & V cleared & If $0<\frac{\gamma}{\beta} \leq 0.4090$ & V cleared \\
& If $0.6259<\frac{\gamma}{\beta}<1$ & Both blocked & If $0.4090<\frac{\gamma}{\beta}<1$ & Both blocked \\
$n=3$ & If $0<\frac{\gamma}{\beta} \leq 0.3967$ & V cleared & If $0<\frac{\gamma}{\beta} \leq 0.1943$ & V cleared \\
& If $0.3967<\frac{\gamma}{\beta}<1$ & Both blocked & If $0.1943<\frac{\gamma}{\beta}<1$ & Both blocked \\
$n=5$ & If $0<\frac{\gamma}{\beta} \leq 0.1798$ & V cleared & If $0<\frac{\gamma}{\beta} \leq 0.0694$ & V cleared \\
$n=11$ & If $0.1798<\frac{\gamma}{\beta}<1$ & Both blocked & If $0.0694<\frac{\gamma}{\beta}<1$ & Both blocked \\
& If $0<\frac{\gamma}{\beta} \leq 0.0411$ & V cleared & If $0<\frac{\gamma}{\beta} \leq 0.0137$ & V cleared \\
$n=25$ & If $0.0411<\frac{\gamma}{\beta}<1$ & Both blocked & If $0.0137<\frac{\gamma}{\beta}<1$ & Both blocked \\
& If $0<\frac{\gamma}{\beta} \leq 0.0081$ & V cleared & If $0<\frac{\gamma}{\beta} \leq 0.0026$ & V cleared \\
\hline
\end{tabular}


surplus decreases in comparison to the initial situation. This occurs for every $n$ and every value in the differentiation ratio. This latter effect on consumers is reinforced since industry profits might fall when products are sufficiently differentiated. Finally, in case industry profits increase, this positive effect on social welfare is offset by the negative effect on consumers. Thus the conclusion is clear: when only strategic effects are considered, the $H$ merger is never socially preferred. On the contrary, after a $V$ merger consumers can be better off depending on how similar composite goods are perceived. Only $V$ mergers that undertake mixed bundling at equilibrium may attain the highest consumer and total surplus. The new firm sets a bundle price lower than the composite good price prior to the merger. In addition, the strategic reaction by outsiders leads to outsider composite good prices decrease with respect to the initial situation. Finally, mix-and-match composite goods have increased their price. Thus, it turns out that CS is higher after the $V$ merger if products are differentiated enough, despite consumption is diverted from the mix-and-match to the bundle and outsider composite goods. Additionally, industry profits might decrease which explains why the clearing threshold is more restrictive under the SW standard. The results about the $V$ merger are partially in line with those in Choi (2008), since at some threshold in the differentiation ratio, it is socially better not to engage in any merger. We find that this threshold is more demanding as the number of component producers increase, the reason is that both SW and CS decline more when a $V$ merger is in place as compared to the decline produced in the initial situation.

\section{Policy implications}

In view of Propositions 1 and 2, there is a clear-cut policy implication regardless of the standard considered: when only strategic effects are reckoned, proposed $V$ mergers have to be always cleared while proposed $H$ mergers must be always forbidden by antitrust authorities.

Therefore, a market failure arises when a proposed $H$ merger would never be approved. In fact, two types of market failure can be considered, one that implies a proposed merger type different to the socially optimal one (i.e. for $0.0958<\frac{\gamma}{\beta}<$ 0.4090 under the SW standard and $n=2$ ), and a second one that implies that no merger is the social maximizing outcome. Finally, when composite goods are very differentiated, no market failure arises as any proposed $V$ merger will be cleared.

To complete the analysis let us think of a situation, which is usually the case, where antitrust authorities have less information than firms involved in a merger. Then, if firms submit a $V$ merger proposal that is not expected at equilibrium, that is for $\frac{\gamma}{\beta}>0.0958$ and $n=2$, antitrust authorities should infer that this $V$ merger will come out with cost efficiencies and, therefore, should be approved. This is an indication that the strategic incentives to merge have being countervailed by efficiency gains (such as production cost savings through economies of scale and scope, improvements in quality or service, reductions in transactional costs or increased incentives for R\&D processes, and so on) anticipated by the firms which are making the $V$ merger more profitable than a $H$ one in that case. Since efficiency gains are good for consumers, antitrust authorities will be more willing to accept the proposed merger. In other words, when firms propose a type of merger different from the equilibrium one, authorities 
face cases where the efficiency effects obtained are substantial to make that merger type preferable.

\section{The effects of a countermerger}

One interesting question raised by a referee is which would be the reaction in the industry after a former merger. In addressing this question we consider that after each type of merger, outsiders might propose a same type merger or a different one. Therefore, three different market structures are analyzed. The first one is the sequential horizontal merger, denoted by $H H$, the second is the sequential vertical merger, denoted by $V V$, and finally a mixed situation with one horizontal and one vertical merger, denoted by $H V$. Regarding the $H H$, consider that the firm producing component $A_{3}$ decides to propose a horizontal merger. It has two options, either to merge with the already formed merger with firms producing components $A_{1}$ and $A_{2}$ or to form an alternative merger with other single component producer, say $A_{4}$. We show that the proposer would prefer to merge with the initial merger rather than forming an alternative one. ${ }^{21}$ This occurs for any $n$ and the firms involved will be better off by forming the merger. The effect of such an extended merger in the market as compared to the situation with one horizontal merger is that outsiders of the same type are better off, while outsiders producing a component of a different type are worse off. Outsiders aggregate profits decrease. However, the effect on total profits including the merger is that the extended merger increase them only if the ratio $\frac{\gamma}{\beta}$ is large enough, noting that the condition is relaxed as the number of firms increase.

Next, consider a sequential vertical merger, in this case we study the market with the initial merger between firms producing components $A_{1}$ and $B_{1}$ and a new one between firms producing components $A_{n}$ and $B_{n}$. The effect in the industry is that the second vertical merger reduces the profits of the initial vertical merger, and also those of outsiders. Finally, industry profits increase only for large enough values of $\frac{\gamma}{\beta}$. As it occurs in the $\mathrm{HH}$ situation, the condition that implies an increase in total profits is less demanding as the number of firms increase. We finally consider the market situation with one horizontal merger between firms producing components $A_{1}$ and $A_{2}$ and a vertical merger between firms producing components $A_{n}$ and $B_{n}$. The effect induced on the market depend on the initial situation. Consider that the initial merger was a $H$ one, then a subsequent vertical merger will imply lower profits for the initial merge, and all the outsiders of any type. Industry profits follow the same pattern as a $V V$ merger. However, if the initial merger is a $V$ one, the effect of a subsequent horizontal merger is to increase profits for all outsiders, and to increase profits of the initial merger and industry profits if the ratio $\frac{\gamma}{\beta}$ is large enough.

In order to illustrate the endogenous merger formation with two steps we present the cases for $n=5, n=11$ and for $n=13$ in the next result.

Result 2 Consider $n=5$, the sequence of endogenous mergers that arise is

(a) $V V$ for $0<\frac{\gamma}{\beta}<0.0694$

(b) $V H$ for $0.0694<\frac{\gamma}{\beta}<0.0741$

(c) HH for $0.0741<\frac{\gamma}{\beta}<1$

${ }^{21}$ Equilibrium expressions and proofs of this subsection are available from the authors upon request. 
Consider $n=11$, the sequence of endogenous mergers that arise is

(a) $V V$ for $0<\frac{\gamma}{\beta}<0.9350$

(b) VH for $0.9350<\frac{\gamma}{\beta}<1$

Consider $n=13$, the sequence of endogenous mergers that arise is $V V \forall \frac{\gamma}{\beta} \in(0,1)$.

The above result indicates that a $V V$ merger arise in more situations when the number of firms increase, being the only one expected for a sufficiently large $n$. The pattern found in Proposition 1 is repeated when the number of firms is bellow 11, that is, when composite goods are very differentiated a second vertical merger is formed, while the horizontal one is added when composite goods are closer, the threshold for finding a second horizontal merger increases with then number of firms. Regarding SW and CS, the effect of a $H H$ merger is always to reduce them with respect to either the initial situation or with respect to the $H$ merger. The effect of a $V V$ merger is to improve welfare and consumer surplus in case of rather differentiated composite goods. The effect of a $V H$ merger is to improve welfare and consumer surplus with respect to either the initial situation or with respect to a $H$ merger if composite products are very differentiated. However, when compared to a $V$ merger, social welfare and consumer surplus always decrease. As a final comment, the proposal of a new horizontal merger in the market will be always blocked while the proposal of a vertical one will be always cleared.

\section{Robustness}

We are now interested on how the results presented above change when we depart from the case presented above if $n=2$. In particular, which is the equilibrium merger and the effects on welfare when either, a) the number of producers differs across components, or b) there are three components in a composite good, or c) components are not fully compatible, or finally d) when there are producers that offer components of different quality.

\section{(a) Differences in the number of producers across components}

Consider an asymmetric industry where, without loss of generality, there are three type $A$ component producers and only two type $B$ component producers. In this market structure, there are two different kinds of horizontal mergers depending on the proposer: one that entails no outsiders of the same type (when the proposer is a type B producer) and another one with one outsider. A first result is that both horizontal mergers plus the vertical one are always profitable with respect to the initial situation. Also, the equilibrium merger depends on who is the proposer as follows: (i) Type B producer proposers will always choose the $H$ merger, the incentives to become a monopolist in one type of component outperform the profits of the vertical merger available. (ii) Type A producer proposers will always prefer a $V$ merger. Therefore, the interplay between the Cournot and the competition effects is very sensitive to the asymmetry in the number of producers of each component. In fact, a $H$ merger in the more concentrated component industry fully monopolize that industry and partially controls all the composite goods in the market, while a $H$ merger in the less concentrated component partially controls a share of the composite goods in the market. 
That difference is enough to make more advantageous a $V$ merger if there is no partial control of all the composite good prices.

Regarding the effect on welfare, the highest level of SW is obtained with the $V$ merger for $0<\frac{\gamma}{\beta}<0.29$ or not clearing any merger otherwise. The highest level of CS is also achieved with the $V$ merger for $0<\frac{\gamma}{\beta}<0.51$ or by not clearing any merger otherwise. Thus, the pattern of the socially preferred outcome is similar to the one in the symmetric model, although the ranges for the differentiation ratio in which the vertical merger is cleared are slightly reduced. Interestingly enough, a type A producer proposer will prefer a $V$ merger in the whole range of the differentiation ratio, allowing for merger clearings in a larger range either considering CS or SW standards, while a type B producer proposer will prefer a $H$ merger which will be never cleared.

\section{(b) Three components}

Consider now that the composite good is formed by three components: A, B and C. In an industry with two producers for each component we will have six independent firms. Three different mergers are analyzed: a $H$ merger, a $V$ merger with the three components of the composite good and another $V$ merger with only two components of the composite good. All of them are always preferred compared to the initial situation of all independent firms. However, we will initially focus on the second type of $V$ merger to be more consistent with the initial setting where only mergers of two firms are considered. Notice that as before, a $H$ merger implies fully monopolization of one component but the adding of one more component to the composite good implies lower margins for the merged firm and also for the outsiders; while a $V$ merger is a less powerful tool to control the composite good market, since now there is no full control of a composite good. As a consequence $V$ mergers become a less attractive option so that only the $H$ merger arises at equilibrium. Regarding SW and CS, similar patterns as in the model with two components arise, but now both ranges in which the vertical merger is optimal for the society are slightly more demanding, more differentiation in the composite good is needed in order to clear a $V$ merger. In case the $V$ merger involved the control of the whole bundle then the $V$ merger option arises at equilibrium for a larger range in the differentiation ratio as compared to the standard model. This is an expected result since a merger of three firms is more profitable than one of two.

\section{(c) Components are not fully compatible}

As noted above $n^{2}$ composite goods can be assembled when components are fully compatible. No compatibility imposes restrictions among the combinations consumers can make. Firms usually establish such restrictions based on technical or physical elements. If this is the case, we will assume that, for example, only components with the same subscript can be assembled leading to a market with only $n$ composite goods. When $n=2$, the no compatibility case reduces the number of composite goods by two. Each firm reacts by increasing its component price since it is not now internalizing competition among the composite goods that use its component leading to less demand per component, although the composite goods remaining in the market are sold more. Since the increase in the output per composite good does not compensate for the reduction in the number of them, consumers are worse off if the market turns 
to be of not compatible components. Social welfare is also reduced, but for firms no compatibility pays off when composite goods are not very differentiated, i.e. for $\frac{\gamma}{\beta}>0.623$. Regarding the equilibrium merger, it is firstly checked that a $H$ merger is always leading to larger profits for participants, however, a $V$ merger does not in any case. That is, $V$ mergers are not yielding enough profits when the differentiation ratio is large, in particular for $\frac{\gamma}{\beta}>0.604$, the increase in demand the merged entity receives induced by the reduction in the bundle price is not compensating initial profits. There are not now mix-and-match composite goods that push profits upwards. Finally, the $V$ merger will arise at equilibrium when composite goods are sufficiently differentiated, that is for $\frac{\gamma}{\beta}<0.261$, the $H$ merger otherwise. Thus, no compatibility reduces the number of composite goods in the market which implies a reduction in profits for the $H$ merger, while the $V$ merger decrease in profits is lower or even it is turned an increase in profits if $\frac{\gamma}{\beta}>0.665$. Then, it can be concluded that the Cournot effect is more intense than the competition effect in a market with few composite goods per firm. ${ }^{22}$ Outsiders are in any case worse off after either merger. Finally and regarding welfare, the conclusions follow the same patterns as in the compatibility case, only $V$ mergers might be cleared. The effect of no compatibility is to increase the range of the clearance for the $V$ merger under both welfare standards. That is, a $V$ merger is always cleared under the CS standard and it is cleared if $\frac{\gamma}{\beta}<0.984$ under the SW standard. Then our policy implications apply to the no compatibility case, all proposed $H$ merger has to be blocked, while all proposed $V$ should be cleared.

\section{(d) Quality differences among components of the same type}

Consider the following extension of the model by assuming two qualities, for instance component $A_{1}^{+}$will have a higher quality modeled as a higher willingness to pay in the utility function. The coefficient of the linear term in the utility function for all composite goods including $A_{1}^{+}$is now $\alpha+\tau$ (where $\tau$ is positive) while for those that do not include it is $\alpha$. The effect of one component of higher quality is to enhance demand for all composite goods including the higher quality component and shift inwards the demand of those not including it. Equilibrium component prices of composite goods including $A_{1}^{+}$increase with respect to the symmetric situation since those composite goods benefit from the increase in quality of one of its components, while the price of component of $A_{2}$ is reduced. Similarly, profits for all firms increase except for the firm producing component $A_{2}$.

The question is how the asymmetry in quality affects the firms decision on which type of merger to undertake. It becomes now relevant to distinguish between the mergers proposed by the high quality producer, that is a $H$ merger between $A_{1}^{+}$and $A_{2}$, or a $V$ merger between $A_{1}^{+}$and $B_{1}$, from those proposed by a low quality one, for instance a $H$ merger between $B_{1}$ and $B_{2}$, or a $V$ merger between $A_{2}$ and $B_{2}$. First note that, typically, the effect of a $H$ merger of any quality type is to increase the prices of the components involved in the merger and to reduce those of the components not involved. Regarding profits, the effect of a $H$ merger of any type is to reduce outsiders profits,

\footnotetext{
22 It is worth noting that for $n=2$ a $V$ merger that undertakes pure bundling in a compatibility situation leads to the same equilibrium prices that one operating in a no compatibility market. For $n>2$ it is not longer true.
} 
and it is also proven that both types of $H$ mergers are profitable. Regarding welfare a $H$ merger among the low quality components is leading to the same conclusions as the symmetric model, it always reduces both CS and SW. However, a $H$ merger proposed by the high quality producer might increase CS when products are very differentiated and the difference in quality is large enough. ${ }^{23}$ There is a shift from low quality composite goods to high quality ones that might favor consumers despite the increase in prices. SW is always lower. Regarding the effect of a $V$ merger on composite good prices, it is now more complex to analyze since after the merger there are five different component prices. After a $V$ merger including the high quality component, the bundle (i.e. $A_{1} B_{1}$ ) is sold at a lower price, but all the other composite goods may either increase or decrease their price. For instance, outsiders' composite good is sold at a lower price if composite goods are not very differentiated, but it can be sold at a higher price if products are very differentiated and there are large differences in quality. Similarly, mix-and-match composite good prices can be reduced instead of increase their price when products are very differentiated and large differences in quality. After a $V$ merger of low quality components, the bundle (i.e. $A_{2} B_{2}$ ) is sold at a lower price, the mix-and-match composite goods are sold at higher prices, while the outsiders composite good is typically sold at lower price except for situations with large quality differences and not very differentiated composite goods.

Finally and undertaking a local analysis in the neighborhood of $\tau=0$, the difference in profits between proposing a $H$ merger and proposing a $V$ one when the proposer is the high quality producer is decreasing in quality showing that small differences in quality are making more likely the proposal of $V$ mergers. Then a $V$ merger is a better instrument for the high quality firm to take advantage of its better quality. The result totally changes when it is the low quality firm the proposer since the difference in profits of proposing a $H$ merger increase with respect to those of proposing a $V$ one, that is a $H$ merger is a better instrument for low quality firms to partially compensate from their disadvantage in quality. Regarding CS and SW, small differences in quality increase the differences in both welfare standards in favor of the $V$ merger regardless of who propose it.

\section{Horizontal mergers with efficiencies}

Now the model is extended to include efficiency effects in case a merger between substitute components occurs and when $n=2$. Because the merging companies' business operations may be very similar, there may be opportunities to join certain operations, such as manufacturing or advertising, and reduce costs. Obviously, cost savings could also be obtained in $V$ mergers, but we focus on the more interesting case since otherwise the conclusion would be that $V$ merger would be more frequently proposed and therefore cleared by antitrust authorities.

The price incentives a merged firm faces after a horizontal merger of differentiated products are of two kinds. The first one is driven by the internalization of competition

\footnotetext{
23 An upper bound on $\tau$ has been considered that ensures that all equilibrium quantities are positive. Therefore, when we are referring to large enough quality differences this restriction has been considered.
} 
between the products sold by the new entity and the second accounts for the potential cost efficiencies derived from the merger. The first effect is positive in the sense that it implies post-merger price increases, while the second is negative since it works in the opposite direction. A post-merger increase in prices would be expected only if the former effect dominates the second.

\section{The price variation index for a composite good market}

To evaluate the unilateral effects derived from a merger, we are going to compute the difference in post and pre-merger equilibrium prices relative to the pre-merger prices as a function of the diversion ratio ${ }^{24}$ from firm i to firm $\mathrm{j}\left(D_{i j}\right)$ and the pre-merger Lerner index $\left(M_{i}\right)$. Obviously, a positive index indicates an increase in prices. In case efficiencies are present, it is possible to disentangle the effect of the increase in prices due to the internalization of competition between the merging firms and the effect of the synergies. The index used allows us to compute the marginal cost reductions (from merger synergies) required to prevent price increases. ${ }^{25}$

Take now a post-merger profit function which allows for efficiencies in the form of synergies affecting marginal costs as follows: $\pi_{A_{1} A_{2}}=\left(p_{1}-c\right)\left(X_{11}+X_{12}\right)+\left(p_{2}-\right.$ $c)\left(X_{21}+X_{22}\right)+E c\left(X_{11}+X_{12}+X_{21}+X_{22}\right)$, where $E$ stands for the merger induced marginal costs savings proportion, where $E<1$. Then, we can easily compute the post-merger equilibrium prices arising from profit maximization accounting for the effect of synergies and denote them by $p^{H s}$ and $q^{H s}$, thus the price of composite goods is $s^{H s}=p^{H s}+q^{H s}$. We are interested in the post-merger percentage increase for the composite good price, ${ }^{26}$ that is $\frac{s^{H s}-s^{I}}{s^{I}}$. As indicated above, the index is the sum of two terms, the first is a function of the diversion ratio from components $A_{1}$ and $A_{2}$, denoted by $D_{12}$, and the pre-merger margin of a single component, denoted by $M$; while the second term is the pass-through rate which is a function of the marginal cost saving measured as a fraction of its price.

The diversion ratio $D_{12}$ is defined as the share of sales lost by merging component $A_{1}$ that is recaptured by the other component $A_{2}$, when the price of the former increases, that is $D_{12}=\frac{\frac{\partial\left(X_{21}+X_{22}\right)}{\partial p_{1}}}{\frac{\partial\left(X_{11}+X_{12}\right)}{\partial p_{1}}}=-\frac{2 \gamma}{\beta+\gamma}$, where the demand of component $A_{2}$ is precisely $X_{21}+X_{22}$ and that of component $A_{1}$ is $X_{11}+X_{12} \cdot{ }^{27}$ Regarding the pre-merger margin

\footnotetext{
24 The diversion ratio is not such a new concept (see Shapiro (1996) and Werden (1996)). Shapiro (2010a) defends that economists have measured diversion from one product to another using cross-elasticity of demand between two products, and agencies have used elasticities to measure "reasonable interchangeability". In fact, it is stated that by 1995 , the DOJ was using the term "diversion ratio" to capture this same concept in a more intuitive way.

25 Among the several indices used to evaluate unilateral effects, the UPPI by Farrell and Shapiro and the CMCR by Werden and Froeb are the most commonly known. Both essentially coincide in a symmetric Bertrand model once the UPPI is computed taking the indirect effects into account, that is including the effect each merging firm's cost reduction has on the other merging firm's price.

${ }^{26}$ Despite firms select component prices the relevant price is the composite good price and not the component price since consumers do not derive any utility from consumption of single components. We will establish their relationship below.

27 It can be easily shown that in a composite good industry the diversion ratio for the general case with $n$ components of the same type is $-\frac{n \gamma}{\beta+\gamma\left(n^{2}-n-1\right)}$.
} 
index of a single component, $M$ is defined as $\frac{p^{I}-c}{p^{I}}$ which is the same as the one resulting for the composite good, $\frac{s^{I}-2 c}{s^{I}}$, just noting that $s^{I}=2 p^{I}$ by the symmetry considered. The pre-merger margin index can be expressed as a function of the diversion ratio and other parameters as follows: $M=\frac{s^{I}-2 c}{s^{I}}=\frac{p^{I}-c}{p^{I}}=\frac{\left(1+D_{12}\right)(\alpha-2 c)}{\left(1+D_{12}\right) \alpha+c}$. Finally the price index that arises is given by

$$
\frac{s^{H s}-s^{I}}{s^{I}}=\frac{1}{2}\left(\frac{p^{H s}-p^{I}}{p^{I}}+\frac{q^{H s}-q^{I}}{q^{I}}\right)=-M \frac{D_{12}}{2\left(3+D_{12}\right)\left(1+D_{12}\right)}-\frac{(1-M) E}{2\left(3+D_{12}\right)} .
$$

Which equals the average of the components' index. As expected there are two opposing terms which allows us to find the CMCR, which is the minimum reduction in the marginal costs as a fraction of the price that ensures a nonincrease of postmerger prices, that is $\varepsilon^{0}=(1-M) E^{0}=\frac{-M D_{12}}{1+D_{12}}>0$. Therefore, it is concluded that all $E>\frac{\varepsilon^{0}}{(1-M)}$ implies a decrease in prices after the merger. The threshold $\varepsilon^{0}$ is increasing in the pre-merger margin index and in the diversion ratio. As the diversion ratio is decreasing in the degree of differentiation, a lower synergy would be required to clear a horizontal merger when composite goods are very differentiated.

Focusing on each component price effects, we have that

$$
\begin{aligned}
& \frac{p^{H s}-p^{I}}{p^{I}}=\left(2+D_{12}\right)\left[-M \frac{D_{12}}{\left(3+D_{12}\right)\left(1+D_{12}\right)}-\frac{(1-M) E}{\left(3+D_{12}\right)}\right] \\
& \frac{q^{H s}-q^{I}}{q^{I}}=\left(1+D_{12}\right)\left[M \frac{D_{12}}{\left(3+D_{12}\right)\left(1+D_{12}\right)}+\frac{(1-M) E}{\left(3+D_{12}\right)}\right]
\end{aligned}
$$

It is interesting to see that the price index for the composite good price is explained by opposing effects on the different component prices. The horizontal merger has an upward effect on $p$ 's while there is a downward effect on $q$ 's absent synergies. Also regarding the pass-through rates the horizontal merger has a negative effect on $p$ 's while the effect is positive on $q$ 's. Since the effect derived from $p$ 's is a direct effect it dominates the induced effect on $q$ 's so the price index for the composite good follows the same pattern than the effect on $p$ 's.

\section{The price variation index for a regular good industry}

Now we are interested in finding whether the variation in prices resulting from a horizontal merger is higher when the market is characterized by composite goods or by regular goods. In order to make the comparison properly we have to consider the same utility function as before and also to eliminate the possibility that consumers choose about components. Thus the representative consumer maximizes utility noting that only products $X_{11}$ and $X_{22}$ will be available. The simplest way to do it is to assume away compatibility between components of the same type and also consider that there are only two firms, each producing one component of each type. That is, firm 1 produces components $A_{1}$ and $B_{1}$ while firm 2 produces components $A_{2}$ and $B_{2}$, therefore only two products are sold provided incompatibility, that is $X_{11}$ and $X_{22}$, as required. We solve the model for the pre-merger situation and when both firms 1 and 2 
merge, where of course only horizontal mergers make sense. Denote by $\bar{s}$ and by $\bar{s} H s$ the equilibrium prices pre-merger and post-merger when efficiencies are resulting after the merger. Also denote by $\bar{D}_{12}$ and $\bar{M}$ the corresponding diversion ratios and initial price margins, where it turns out that $\bar{D}_{12}=\frac{-\gamma}{\beta}$ and $\bar{M}=\frac{\bar{s}^{I}-2 c}{\bar{s}^{I}}=\frac{\left(1+\bar{D}_{12}\right)(\alpha-2 c)}{\left(1+\bar{D}_{12}\right) \alpha+2 c}$. Therefore the price variation index corresponding to the regular good industry is

$$
\frac{\bar{s}^{H s}-\bar{s}^{I}}{\bar{s}^{I}}=-\bar{M} \frac{\bar{D}_{12}}{2\left(1+\bar{D}_{12}\right)}-\frac{(1-\bar{M}) E}{2} .
$$

Where $\bar{\varepsilon}^{0} \equiv\left(\frac{2 c \bar{E}^{0}}{\bar{s}^{I}}\right)=(1-\bar{M}) \bar{E}^{0}=\frac{-\bar{M} \bar{D}_{12}}{1+\bar{D}_{12}}>0$, which is the CMCR. And it is concluded that all $E>\frac{\bar{\varepsilon}^{0}}{(1-\bar{M})}$ implies a decrease in prices after the merger. ${ }^{28}$

\section{Comparison between price variation indices}

First of all it is important to comment that the diversion ratio for composite goods is greater (in absolute terms) than that of the regular good industry, $D_{12}>\bar{D}_{12}$. The reason is that an increase in one component price affects two composite goods. Thus the opportunity cost of that price increase in terms of sales in favor of the other component of the same type is higher as compared with the regular product market. Secondly, the price margin ratio for the composite good market is greater than that the regular market, $M>\bar{M}$. Therefore, four independent firms in a composite good market have more market power than a duopoly in a regular market. Note that higher diversion ratios and higher price margin ratios are conditions that tend to increase the upward pricing pressure after the merger. Thus as products become more substitutes the pressure on prices increases and this is true for both type of goods.

Thirdly, the following proposition is reached:

Proposition 3 Considering a horizontal merger, the marginal cost saving proportion required to not increase prices is greater for a composite good industry than the one required for a regular good industry. In other words, $E^{0}>\bar{E}^{0}$.

The above result is useful for antitrust authorities since it advises them to be more demanding when dealing with horizontal mergers in composite goods industries. Note that this difference is rooted to the higher diversion ratio and margin that arise in composite good industries.

Finally, to compare the two indices just note that horizontal mergers in composite good industries are less effective in passing efficiencies derived from the merger to consumers, since pass-through rates are larger for regular good industries, that is $\frac{(1-M) E}{2\left(3+D_{12}\right)}<\frac{(1-\bar{M}) E}{2}$. Also and in case of no realized efficiencies after the merger, that is for $E=0$, an interesting result is that the comparison among both indices is not univocal and depends on the degree of product differentiation and on the size of the $\frac{\alpha}{c}$ ratio. In particular, the price index in composite-good industries is greater if and

\footnotetext{
28 Note that the equality for the case of symmetry in page 9 in Shapiro (2010b) is the same as the expression 7 in the text once we consider the diversion ratio with its sign and not in absolute value. Solving for $E$, we find the same expression as Eq. 6 in Werden (1996).
} 
only if $\frac{\alpha}{c}>\frac{\beta+\gamma}{\beta-\gamma}$. A sufficient condition is that the price index in composite-good industries is greater for all $\frac{\alpha}{c}$ if $\frac{\gamma}{\beta}<\frac{1}{3}$.

\section{Conclusions}

This paper studies merging behavior in a composite good industry allowing firms to choose the type of partner, either a complementary or a substitute component producer. Previous analysis has focused on just one type of merger and papers on composite goods have considered only the possibility of complementary mergers. We find that when the number of firms is relatively low, i.e. less than eleven per component which implies less than 121 composite goods in the market, vertical mergers arise at equilibrium only if composite goods are very differentiated, while horizontal mergers are preferred otherwise. If the number of firms is greater than or equal than this threshold, only vertical mergers arise at equilibrium. In terms of welfare a simple policy implication is derived: a proposed vertical merger will be always allowed by antitrust authorities under any standard, either the consumer surplus or the social welfare one, while a horizontal merger will never be when only strategic effects are taken into account. Therefore, we identify a market failure since horizontal mergers when proposed are never allowed. This never happens in case a vertical merger is proposed. Another interesting advise for antitrust authorities is that if they receive notifications of vertical mergers when products are close substitutes and the number of firms is not large, they should conclude that some efficiencies are associated to vertical mergers since they would not otherwise be proposed. Finally, the higher the number of firms in the market, the stricter the condition for a vertical merger to be approved, under both standards, Consumer Surplus or Social Welfare. The possibility of a countermerger is also studied, which will be the response in the industry after a merger. We find that a similar pattern as in the baseline model, since a second horizontal merger will follow if the number of firms is not too large and composite goods are good substitutes, while a vertical one follows when either composite products are very differentiated or when the number of firms is large. The policy implication remains unaltered. Several robustness checks are carried out under the baseline model when $n=2$ to analyze whether including more producers in only one component, or adding a third component, or limiting compatibility, or introducing quality differences imply significant changes in the results. The basic conclusion is that all of these new assumptions are imposing asymmetries that make important who is the proposer of a merger thus resulting in interesting scenarios. Basically the baseline model results are not qualitatively altered.

Coming back to policy implications, notice that horizontal mergers are commonly proposed and usually accepted in case there is no substantial lessening of competition or the merger is a necessary condition to achieve efficiency gains. Since the isolated strategic effects do not allow to clear horizontal mergers, we resort to considering efficiency effects linked to horizontal mergers to check the conditions antitrust authorities should impose to clear them for the case of $n=2$. To tackle this issue we consider a price index to evaluate unilateral effects of a merger which takes into account, on the one hand, the diversion ratio and the pre-merger margin index and, on the other, the pass-through rate. We find that both the diversion ratio and the pre-merger margin 
index are greater in a composite good industry, compared to a regular good industry. Thus, despite being counter intuitive, firms' market power is greater in a four-firm composite good industry than in a standard duopoly of a regular good. The passthrough rate, however, is lower in a composite good industry. An important result is that the marginal cost saving required for a horizontal merger in order not to increase prices is greater in a composite good industry than in a regular good one. Antitrust authorities should request, therefore, higher savings levels in the case of horizontal mergers in composite good markets.

It will be interesting to study in future research efficiency effects when components can give some utility to consumers by themselves, not only if they are combined and used inside a composite good. Moreover, a policy maker can be incorporated to the model, to study the implications of a policy aimed to make firms reduce post-merger prices or to subsidize firms involved in desirable mergers for the society.

Acknowledgments We would like to thank the Editor Victor Aguirregabiria and one referee for their valuable suggestions and comments that have substantially improved the paper. Also, we would like to thank the comments and the advice given by Ricardo Flores-Fillol and Rafael Moner-Colonques from which this paper has profited very much. Jose J. Sempere-Monerris gratefully acknowledges financial support from the Spanish Ministry of Economy and Competitiveness under the project the project ECO2013-45045-R and support from Generalitat Valenciana under the project PROMETEOII/2014/054.

Open Access This article is distributed under the terms of the Creative Commons Attribution License which permits any use, distribution, and reproduction in any medium, provided the original author(s) and the source are credited.

\section{Appendix: Equilibrium expressions}

\section{Horizontal merger}

$A_{1}$ and $A_{2}$ producers merge. Three qualitatively different FOC will arise by making use of the symmetry in the model, leading to the following three equilibrium component prices after solving the system:

(i) The price of component $\mathrm{A}$ set by the merged firm, $p_{M}^{H}(n)$, where $H$ denotes horizontal and $M$ identifies the merged firm.

(ii) The price of component A set by the outsiders, $p_{O}^{H}(n)$, where $O$ denotes outsiders.

(iii) The price of component $\mathrm{B}$ set by also outsiders to the merger, $q_{O}^{H}(n)$.

FOC's for outsiders have the same shape as in the initial case while those for the merged firm now incorporates the internalization of competition between component $A_{1}$ and $A_{2}$ resulting in a smaller marginal effect of the component price on total component demand. That is, for the case of $p_{1}$ the FOC reads,

$$
\sum_{\forall j} X_{1 j}=\left(p_{1}-c\right) \frac{n\left(\beta+\left(n^{2}-2 n-1\right) \gamma\right)}{(\beta-\gamma)\left(\beta+\left(n^{2}-1\right) \gamma\right)} .
$$

The equilibrium component prices follow:

$$
p_{M}^{H}(n)=\frac{(\alpha-2 c)(\beta-\gamma)\left(\beta+\left(n^{2}-n-1\right) \gamma\right)\left(2 \beta+\left(2 n^{2}-n-2\right) \gamma\right)}{2\left(3 \beta^{3}+\left(7 n^{2}-7 n-10\right) \beta^{2} \gamma+\left(5 n^{4}-10 n^{3}-11 n^{2}+14 n+11\right) \beta \gamma^{2}+\left(n^{6}-3 n^{5}-3 n^{4}+10 n^{3}+4 n^{2}-7 n-4\right) \gamma^{3}\right)}+c
$$




$$
\begin{aligned}
& p_{O}^{H}(n)=\frac{(\alpha-2 c)(\beta-\gamma)\left(\beta+\left(n^{2}-n-1\right) \gamma\right)^{2}}{3 \beta^{3}+\left(7 n^{2}-7 n-10\right) \beta^{2} \gamma+\left(5 n^{4}-10 n^{3}-11 n^{2}+14 n+11\right) \beta \gamma^{2}+\left(n^{6}-3 n^{5}-3 n^{4}+10 n^{3}+4 n^{2}-7 n-4\right) \gamma^{3}}+c \\
& q_{O}^{H}(n)=\frac{(\alpha-2 c)(\beta-\gamma)\left(\beta^{2}+\left(2 n^{2}-2 n-3\right) \beta \gamma+\left(n^{4}-2 n^{3}-2 n^{2}+2 n+2\right) \gamma^{2}\right)}{3 \beta^{3}+\left(7 n^{2}-7 n-10\right) \beta^{2} \gamma+\left(5 n^{4}-10 n^{3}-11 n^{2}+14 n+11\right) \beta \gamma^{2}+\left(n^{6}-3 n^{5}-3 n^{4}+10 n^{3}+4 n^{2}-7 n-4\right) \gamma^{3}}+c
\end{aligned}
$$

Profits for the merged firm, outsiders of the same component type and outsiders of the other component type are now,

$$
\begin{aligned}
\pi_{M}^{H}(n) & =\frac{2 n\left(\beta+\left(n^{2}-2 n-1\right) \gamma\right)\left(p_{M}^{H}(n)-c\right)^{2}}{(\beta-\gamma)\left(\beta+\left(n^{2}-1\right) \gamma\right)} \\
\pi_{O A}^{H}(n) & =\frac{n\left(\beta+\left(n^{2}-n-1\right) \gamma\right)\left(p_{O}^{H}(n)-c\right)^{2}}{(\beta-\gamma)\left(\beta+\left(n^{2}-1\right) \gamma\right)} \\
\pi_{O B}^{H}(n) & =\frac{n\left(\beta+\left(n^{2}-n-1\right) \gamma\right)\left(q_{O}^{H}(n)-c\right)^{2}}{(\beta-\gamma)\left(\beta+\left(n^{2}-1\right) \gamma\right)}
\end{aligned}
$$

\section{Vertical merger}

$A_{1}$ and $B_{1}$ producers merge. When mixed bundling is considered the new entity will set three different prices. Those for each component type and another one for the bundle. Three qualitatively different FOCs will arise by making use of the symmetry in the model, which lead to the following:

(i) The price of components $A_{1}$ and $B_{1}, p_{1}^{V}=q_{1}^{V}=p_{M}^{V}(n)$, where $V$ refers to vertical.

(ii) The bundle price, $s_{b}^{V}(n)$.

(iii) The component prices $A_{i}$ and $B_{j}$ set by outsiders are $p_{i}^{V}=q_{j}^{V}=p_{O}^{V}(n)$ with $i, j \neq 1$.

The equilibrium prices are,

$$
\begin{aligned}
& p_{M}^{V}(n)=\frac{(\alpha-2 c)(\beta-\gamma)\left(2 \beta+\left(2 n^{2}-n-2\right) \gamma\right)}{2\left(3 \beta^{2}+\left(4 n^{2}-4 n-5\right) \beta \gamma+\left(n^{2}-2 n-1\right)\left(n^{2}-2\right) \gamma^{2}\right)}+c \\
& s_{b}^{V}(n)=\frac{(\alpha-2 c)(\beta-\gamma)\left(3 \beta+\left(3 n^{2}-2 n-3\right) \gamma\right)}{2\left(3 \beta^{2}+\left(4 n^{2}-4 n-5\right) \beta \gamma+\left(n^{2}-2 n-1\right)\left(n^{2}-2\right) \gamma^{2}\right)}+c \\
& p_{O}^{V}(n)=\frac{(\alpha-2 c)(\beta-\gamma)\left(\beta+\left(n^{2}-n-1\right) \gamma\right)}{3 \beta^{2}+\left(4 n^{2}-4 n-5\right) \beta \gamma+\left(n^{2}-2 n-1\right)\left(n^{2}-2\right) \gamma^{2}}+c
\end{aligned}
$$

Making use of the three FOC, profits at equilibrium can be written as,

$$
\begin{aligned}
& \pi_{M}^{V}(n)=\frac{\left(\beta+\gamma\left(n^{2}-2\right)\right)\left(s_{B}^{V}(n)-c\right)^{2}+2(n-1)\left(\beta+\gamma\left(n^{2}-2 n+1\right)\right)\left(p_{M}^{V}(n)-c\right)^{2}-4 \gamma(n-1)\left(s_{B}^{V}(n)-c\right)\left(p_{M}^{V}(n)-c\right)}{(\beta-\gamma)\left(\beta+\left(n^{2}-1\right) \gamma\right)} \\
& \pi_{O}^{V}(n)=\pi_{O A}^{V}(n)=\pi_{O B}^{V}(n)=\frac{n\left(\beta+\left(n^{2}-n-1\right) \gamma\right)\left(p_{O}^{V}(n)-c\right)^{2}}{(\beta-\gamma)\left(\beta+\left(n^{2}-1\right) \gamma\right)}
\end{aligned}
$$




\section{Pure bundling}

In case of pure bundling, although there are $n \times n$ firms only $(n-1) \times(n-1)$ composite goods plus the bundle can be purchased. Besides, only two different equilibrium prices are set, the bundle price, denoted by $s_{p b}^{V}(n)$, and the outsiders component prices, $p_{p O}^{V}(n)$. The expressions for those prices and profits are:

$$
\begin{aligned}
s_{p b}^{V}(n) & =\frac{(\alpha-2 c)(\beta-\gamma)(3 \beta+(n-1)(3 n-4) \gamma)}{2\left(3 \beta^{2}+(n-2)(4 n-1) \beta \gamma+(n-1)(n(n-1)(n-3)+1) \gamma^{2}\right)}+c \\
p_{p O}^{V}(n) & =\frac{(\alpha-2 c)(\beta-\gamma)(2 \beta+(2 n(n-2)+1) \gamma)}{2\left(3 \beta^{2}+(n-2)(4 n-1) \beta \gamma+(n-1)(n(n-1)(n-3)+1) \gamma^{2}\right)}+c \\
\pi_{p M}^{V}(n) & =\frac{(\alpha-2 c)^{2}(\beta-\gamma)(\beta+n(n-2) \gamma)(3 \beta+(n-1)(3 n-4) \gamma)}{4\left(\beta+(n-1)^{2} \gamma\right)\left(3 \beta^{2}+(n-2)(4 n-1) \beta \gamma+(n-1)(n(n-1)(n-3)+1) \gamma^{2}\right)^{2}} \\
\pi_{p O}^{V}(n) & =\frac{(n-1)(\alpha-2 c)^{2}(\beta-\gamma)(\beta+(n-1)(n-2) \gamma)(2 \beta+(2 n(n-2)+1) \gamma)}{4\left(\beta+(n-1)^{2} \gamma\right)\left(3 \beta^{2}+(n-2)(4 n-1) \beta \gamma+(n-1)(n(n-1)(n-3)+1) \gamma^{2}\right)^{2}}
\end{aligned}
$$

\section{Social Welfare}

To compute the expressions for Social Welfare (SW) and Consumer Surplus (CS) corresponding to each situation we will use a reformulation of the utility function in the main text. For the initial situation case, symmetry implies that $\sum_{\forall i}\left(\sum_{\forall j} X_{i j}\right)=$ $n^{2} X_{i j}^{I}$ leading to the following expressions for welfare and consumer surplus:

$$
\begin{aligned}
& S W^{I}(n)=n^{2}\left((\alpha-2 c) X_{i j}^{I}-\frac{\beta+\left(n^{2}-1\right) \gamma}{2}\left(X_{i j}^{I}\right)^{2}\right) \\
& C S^{I}(n)=S W^{I}(n)-2 n \pi^{I}(n)
\end{aligned}
$$

Similarly, in the case of a Horizontal merger between the two firms producing components $A_{1}$ and $A_{2}$, there are two different equilibrium demands those corresponding to the composite goods formed with components produced by the merger, denoted by $X_{M}^{H}$, and the ones corresponding to outsiders of the same type, denoted by $X_{O A}^{H}$, such that the $\sum_{\forall i}\left(\sum_{\forall j} X_{i j}\right)=n\left(2 X_{M}^{H}+(n-2) X_{O A}^{H}\right)$. Social welfare and Consumer surplus read,

$$
\begin{aligned}
S W^{H}(n)= & n\left((\alpha-2 c)\left(2 X_{M}^{H}+(n-2) X_{O A}^{H}\right)\right. \\
& -\frac{\beta-\gamma}{2}\left(2\left(X_{M}^{H}\right)^{2}+(n-2)\left(X_{O A}^{H}\right)^{2}\right) \\
& -\frac{\gamma}{2} n\left(2 X_{M}^{H}+(n-2)\left(X_{O A}^{H}\right)^{2}\right) \\
C S^{H}(n)= & S W^{H}(n)-\pi_{M}^{H}(n)-(n-2) \pi_{O A}^{H}-n \pi_{O B}^{H}
\end{aligned}
$$

Finally, for the case of a Vertical merger there are three different equilibrium demands: the one corresponding to the bundle sold by the merger, denoted by $X_{b}^{V}$, that corresponding to composite goods sold by the merger, denoted by $X_{M}^{V}$, and the one corresponding to the composite goods sold by outsiders, denoted by $X_{O}^{V}$. Notice that 
now the sum of demands for each component of type $A$ differs depending on whether it is the one produced by the new firm, $\sum_{\forall j} X_{1 j}=X_{b}^{V}+(n-1) X_{M}^{V}$ or those produced by outsiders, $\sum_{\forall j} X_{i j}=X_{M}^{V}+(n-1) X_{O}^{V}, \forall i \neq 1$. Adding for all $i$, $\sum_{\forall i}\left(\sum_{\forall j} X_{i j}\right)=X_{b}^{V}+2(n-1) X_{M}^{V}+(n-1)^{2} X_{O}^{V}$. Social welfare and Consumer surplus read,

$$
\begin{aligned}
S W^{V}(n)= & (\alpha-2 c)\left(X_{b}^{V}+2(n-1) X_{M}^{V}+(n-1)^{2} X_{O}^{V}\right) \\
& -\frac{\beta-\gamma}{2}\left(\left(X_{b}^{V}\right)^{2}+2(n-1)\left(X_{M}^{V}\right)^{2}+(n-1)^{2}\left(X_{O}^{V}\right)^{2}\right) \\
& -\frac{\gamma}{2}\left(X_{b}^{V}+2(n-1) X_{M}^{V}+(n-1)^{2} X_{O}^{V}\right)^{2} \\
C S^{V}(n)= & S W^{V}(n)-\pi_{M}^{V}(n)-2(n-1) \pi_{O}^{V}(n)
\end{aligned}
$$

\section{References}

Banal-Estañol A, Macho-Stadler I, Seldeslachts J (2008) Endogenous mergers and endogenous efficiency gains: the efficiency defence revisited. Int J Ind Organ 26:69-91

Beggs AW (1994) Mergers and malls. J Ind Econ 42(4):419-428

Cabral L (2003) Horizontal mergers with free-entry: why cost efficiencies may be a weak defense and asset sales a poor remedy. Int J Ind Organ 21:607-623

Choi JP (2008) Mergers with bundling in complementary markets. J Ind Econ 56(3):553-577

Deneckere R, Davidson C (1985) Incentives to form coalitions with Bertrand competition. RAND J Econ 16(4):473-486

Economides N, Salop SC (1992) Competition and integration among complements, and network market structure. J Ind Econ 40(1):105-123

Farrell J, Shapiro C (1990) Horizontal mergers: an equilibrium analysis. Am Econ Rev 80(1):107-126

Farrell J, Shapiro C (2010) Antitrust evaluation of horizontal mergers: an economic alternative to market definition. B. E. J. Theor. Econ. Pol. Perspect. 10(1):1-39

Flores-Fillol R, Moner-Colonques R (2011) Endogenous mergers of complements with mixed bundling. Rev Ind Organ 39(3):231-251

Froeb LM, Werden GJ (1998) A robust test for consumer welfare enhancing mergers among sellers of a homogeneous product. Econ Lett 58:367-369

Gaudet G, Salant SW (1992) Towards a theory of horizontal mergers. In: Norman G, La Manna M (eds) The new industrial economics. Edward Elgar Publishers, UK, pp 137-158

Gayle PG, Le HB (2013) Measuring merger cost effects: evidence from a dynamic structural econometric model, working paper, Kansas State University, Department of Economics

Harrison T (2011) Do mergers really reduce costs? Evidence from hospitals. Econ Inq 49(4):1054-1069

Kamien MI, Zang I (1990) The limits of monopolization through acquisition. Q J Econ 105(2):465-499

Motta M (2004) Competition policy. Theory and practice. Cambridge University Press, Cambridge

Motta M, Vasconcelos H (2005) Efficiency gains and myopic antitrust authority in a dynamic merger game. Int J Ind Organ 23:777-801

Perry MK, Porter RH (1985) Oligopoly and the incentives for horizontal merger. Am Econ Rev 75(1):219227

Röller LH, Stennek J, Verboven F (2001) Efficiency gains from mergers. Eur Econ 5:31-127

Salant SW, Switzer S, Reynolds RJ (1983) Losses from horizontal merger. The effects of an exogenous change in industry structure on Cournot-Nash equilibrium. Q J Econ 98(2):185-199

Shapiro C (1996) Mergers with differentiated products. Antitrust 10:23-30

Shapiro C (2010a) The 2010 horizontal merger guidelines: from Hedgehog to Fox in forty years. Antitrust Law J 77:701-759 
Shapiro C (2010b) Unilateral effects calculations. University of California at Berkeley, Mimeo Spector D (2003) Horizontal mergers, entry, and efficiency defences. Int J Ind Organ 21:1591-1600 Tirole J (2005) The analysis of tying cases: a primer. Compet Policy Int 1(1):1-25

U.S. Department of Justice and the Federal Trade Commission (2010) Horizontal merger guidelines. http:// www.justice.gov/atr/public/guidelines/hmg-2010.html

Vasconcelos H (2010) Efficiency gains and structural remedies in merger control. J Ind Econ 58(4):742-766

Werden G (1996) A robust test for consumer welfare enhancing mergers among sellers of differentiated products. J Ind Econ 44(4):409-413

Werden G, Froeb L (1998) The entry-inducing effects of horizontal mergers. J Ind Econ 46(4):525-543 